\title{
Cross-cultural Communication Competence for Science and Engineering College Students: Survey \& Proposal
}

\author{
Mei Guo \\ School of Foreign Languages, Dalian University of Technology, Dalian, China \\ Yuan Sun \\ Dalian University of Technology, Dalian, China
}

\begin{abstract}
A survey conducted recently in a university in Dalian indicates that the lack of cross-cultural communication competence is a serious problem among the undergraduates of science and engineering, and in the meantime suggests that finding out proper scheme for training cross-cultural communication skills should be high on the agenda. Based on the results of the survey and the status quo of undergraduates' English skills, this article provides a series of probable methods to improve cross-cultural communication teaching.
\end{abstract}

Index Terms - cross-cultural communication, communication skills, English teaching

\section{INTRODUCTION}

Cross-cultural communication refers to a social phenomenon where communication occurs among different native language speakers coming from multicultural background. As international interflow happens much more widely and frequently, cross-cultural study is becoming a new hot spot for foreign language teachers. And many of them have realized that the ability to make a qualified language learner is to understand the culture differences well rather than master specific grammars or words.

According to a survey by Hu Wenzhong (2005), 2285 articles were published in various academic journals between 1995-2004, featuring issues of intercultural communication and foreign language teaching. However, in spite of growing appeals for the incorporation of intercultural communication into the English language education, no breakthrough has been made in systemic and theoretical construction and original researches are still much in expectation. (Song, 2008) Based on the results of the survey conducted among the undergraduates of science and engineering and the status quo of their cross-cultural communication competence, this article provides a series of probable methods to improve cross-cultural communication teaching.

\section{SURVey of Undergraduates' Cross-CUltural COMMUNICATION COMPETENCE}

This survey, which is conducted by anonymous test paper, is intended to get a general idea of the undergraduates' skills in cross-culture communications, and to discover the obstacles to cross-cultural communicating based on the status quo, so that we can find out an effective scheme to improve language teaching in college.

\section{A. Contents:}

The test paper involves the culture of daily talking, vocabularies, common senses and other signs for expressions, for instance, body language in the English language. Thirty questions are divided into three parts based on the three levels of language learning, the level of Recognition, the level of Behavior and the level of Consciousness. The first two parts are presented in the form of 'True or false' and the last part is in multiple-choice.

\section{B. Participants:}

We surveyed 360 freshmen majoring in science and engineering who have scored no less than $75 \%$ in the entrance exam, which means they have almost no difficulty in reading the test paper. So the results could be more reliable because they are not much influenced by literal understanding difficulties.

\section{Results:}

The statistics are presented in the form of tables. 
TABLE 1

DAILY COMMUNICATION

\begin{tabular}{|l|l|l|}
\hline CONTENTS & AMOUNT & ERROR RATE \\
\hline Greeting, Introducing, \& Farewell & 3 & $26.47 \%$ \\
\hline Addressing & 1 & $24.57 \%$ \\
\hline Inviting \& Appreciating & 2 & $52.47 \%$ \\
\hline Congratulating & 2 & $36.14 \%$ \\
\hline Visiting \& Table Manners & 6 & $40.14 \%$ \\
\hline Giving and Receiving Gifts & 3 & $44.76 \%$ \\
\hline Intent & 3 & $44.29 \%$ \\
\hline
\end{tabular}

TABLE 2

VOCABULARY

\begin{tabular}{|l|l|l|}
\hline CONTENTS & AMOUNT & ERROR RATE \\
\hline Implied Meaning of Colors & 1 & $50 \%$ \\
\hline Implied Meaning of Animals & 1 & $40.29 \%$ \\
\hline Idiom & 1 & $26.29 \%$ \\
\hline Others & 1 & $23.43 \%$ \\
\hline
\end{tabular}

TABLE 3

CULTURAL SENSE

\begin{tabular}{|l|l|l|}
\hline CONTENTS & AMOUNT & ERROR RATE \\
\hline Festival & 1 & $21.14 \%$ \\
\hline Sensitive Topic & 1 & $37.71 \%$ \\
\hline Family Concept & 1 & $28.86 \%$ \\
\hline
\end{tabular}

TABLE 4

NON-VERBAL COMMUNICATION

\begin{tabular}{|l|l|l|}
\hline CONTENTS & AMOUNT & ERROR RATE \\
\hline Eye Contact & 1 & $61.14 \%$ \\
\hline Gesture & 1 & $21.71 \%$ \\
\hline Pause \& Silence & 1 & $30.57 \%$ \\
\hline
\end{tabular}

TABLE 5

AVERAGE ERROR RATE FOR EACH CHAPTER

\begin{tabular}{|l|l|l|}
\hline CONTENT & AMOUNT & AVERAGE ERROR RATE \\
\hline Daily Communication & 20 & $42.71 \%$ \\
\hline Vocabulary & 4 & $35 \%$ \\
\hline Cultural Sense & 3 & $29.24 \%$ \\
\hline Non-verbal Communication & 3 & $37.8 \%$ \\
\hline
\end{tabular}

\section{Analysis:}

The statistics show that the error rate is high, especially in the 'Daily Communication' part with an average error rate of $42.71 \%$. The obstacles of cross-cultural communication are mainly aroused by the lack of native customs. And these reasons contribute to the problem.

First, the expressions are greatly influenced by the Chinese language, the participants' mother tongue. Most students were brought up in a purely Chinese-speaking society which leaves them a strong habit to think and express something in the Chinese traditional way.

Example 1. Mary is a foreign student in China. She met Li Mei and said to her: "I was told that you won the 100-meter race in the track meet this morning. Congratulations." Li replied, "Just lucky." (No.6 in appendix)

The simplest but correct answer is 'Thank you!' However, some students consider 'Just lucky.' is right. In Chinese traditions, citizens have been told to be modest since the time they were born. Admitting being outstanding is somewhat offensive, which is not the same case in western countries. And in the addressing aspect, Chinese traditions also confuse our participants.

Example 2. Mrs. Smith was about the same age as Li Mei’s grandmother, so immediately Li called her "Grandma." (No.8 in appendix)

$24.57 \%$ think that 'Grandma' is correct. In China, children address an adult as 'Uncle', 'Aunt', 'Grandpa' or 'Grandma' due to the adult's age. While in western countries, the proper addressing in this question is just' Mrs. Smith'

In most cases, students can hardly remind themselves how a native speaker expresses it in his traditions, or even they could, they might be still unable to express it properly. Actually, the lack of cultural knowledge makes them just have no idea what the proper way is. And the combination of the English language and the Chinese speaking customs will make the expression confusing and should be avoided.

Second, Chinese students have poor knowledge of English customs, especially for the science and engineering students. Only a low rent of participants has ever read English original works, and few of them paid attention to the cultural differences in them. So, when it comes to the questions related to customs, they make mistakes frequently. 
Example 3. If you are a male and introduced to an English speaking lady, you do not take the initiative in shaking hands unless she holds out her hand first. (No.13 in appendix)

Correct. This shows the respect to the female in western countries.

Example 4. When you walk with a close friend with the same gender as yours in the street, you intimately put your arm around your friend's shoulders or hand while walking. (No.15 in appendix)

In China, this shows the good relationship between you and your friend, but in the Western, you two may be considered as homosexuality.

Example 5. Halloween Day in the West is similar to a festival in China, and this might be appendix)

\section{A .Lantern Festival B. Dragon Boat Festival C. Zhongyuan Festival D. the Double Ninth Festival}

Some participants didn't choose C, and according to interview, they thought that Halloween was somewhat entertaining while Zhongyuan festival was a mournful one. Though there are some entertainments like dressing up as ghosts and trick or treat at Halloween, this festival essentially tends to sacrifice those gods who dominate their lives and in memory of the dead people. It is said that the dead will come from the other world on that day, and both festivals are totally the same in this aspect.

Third, the lack of English speaking experiences is another main reason. Never exposed to the English speaking environment, students can't realize the meanings of some native signs like interruption-oriented, solidarity, silence-avoidance, hesitation, reformulation repetitions, and so on.

Example 6. When someone else shows you a thumps-up gesture, he means "You're so great." (No.25 in appendix)

Though the answer is right and thumps-up gesture is regarded internationally as a sign of appreciation, it depends. Actually, in some western countries including the US, thumps-up also means you want a free ride. And in the Middle East, it indicates insulting and provoking. If a student has never been told such taboos or experienced the real communication, he can easily arise misunderstandings and turn the communication down.

Last, the examination-oriented education system forces high school teachers to focus only on grammar and other key points to the exam. We found that even if a student were an excellent scorer in the College Entrance Examination, he might be unable to read out an easy paragraph where no new words could be found. The poor fact is, since there is no oral test or listening test in the College Entrance Examination and no conditions to have one, Students ignore these scoreless but significant items in English learning. In some high schools in China, English lessons are simplified as memorizing words, phrases and grammar knowledge, no English could be heard in an English lesson. Inevitably, regarding words and grammars as everything of a language will certainly costs them the best chance to improve useful English skills.

\section{Proposal for Cross-Cultural Communicative Approach to English Teaching}

To overcome the obstacles mentioned above, more culture teaching in class may do a help. According to Psychology, as we are listening, reading or gaining information through other channels, the brain will associate the new information with stored knowledge and familiar experiences. So, whether a listener can fully understand a conversation largely depends on how much knowledge his brain has stored. In this way, enough culture teaching in class is undoubtedly necessary.

\section{A. Speaking \& Listening}

Speaking and listening is one of the fundamental language skills. It plays an important role both in our daily life and in language learning, which can perfectly cater to the exam-only high school students now in college. Additionally, this course intends to arouse students' awareness of cultural differences occurring in communications. Teachers shall choose some typical listening materials and when it comes to knowledge associated with culture during listening, they shall directly highlight and explain it. Meanwhile, creating various situations like farewell, greeting, appreciation, etc., for students to practise oral English can effectively improve their skills in real communications. Besides, teachers must remind them that not only oral speaking belongs to communication skills, but body languages, for examples, facial expressions, gesture and sign of other parts of our body count, as well. Specifically, these forms of teaching may do a help:

Conversation plays the most frequent role in daily communications. It is a useful tool to establish relationships, acquire information from others and solve the problems. This is a method for both speaking and listening exercise. While arranging the conversation, teachers could provide a topic first. It could be anything that the students may be interested in, for instance, drama, video games and delicious food etc. Arrange them into small groups of 4 to 6 so that they can hear and see each other. Encourage every student to present his ideas. There are a few things that the teachers should take under control: ensuring every student is involved in and they are talking in English, avoiding argument, and highlighting the cultural features in the conversation.

Storytelling can grasp all the students' attention. When enjoying a good story, students could not only get some ideas of other's life but compare to their own life, as well. This makes the culture differences in the story much more impressive. Although storytelling can't do much help to speaking, since the story is presented by the teacher or someone professional, it greatly benefits listening. Also, these tips may make the lesson better: 
Never read out or refer to a note. Avoiding doing so could give the audience more expectations and eye contacts. Prepare it carefully. You could record yourself and then listen to the tape to find out where you could do better. You can ask an excellent student to be the storyteller, but you should ensure the quality of his story and pronunciation.

Oral report provides a chance for every student to speak in turn in front of the whole class. Not only could this benefit students' speaking, but give them more confidence in public announcing. Besides, teachers can also get a general idea of each student's speaking ability. Here are some tips:

Arrange one or two students to give the report each lesson, so that every student can get a chance to speak and it will not occupy too much time of the class. Suggest bring notes instead of the whole script of the report. Do not recite all of the report, for it will make the student more nervous and may get stuck if he forgets his lines. Give a short remark after each report. Praises or suggestions show your respect and could give the student more confidence.

Role play involves many practical skills and no forms of other practice could be more realistic than a role play. In a well set background, students could experience the customs, facial expressions, eye contact, gestures and other real factors in a communication. So, if time permitted, role play is the best choice.

Before the class, you'd better choose the script first. An adlib play for students to present instantly in class may cause some problems. The most obvious problem is that an adlib play constructed temporarily by the students cannot ensure the lines to be idiomatic. The script itself ought to contain fewer new words and more cultural features. Not all of the students could take part in the play, so prepare some questions for the audience. Don't interrupt the play. Allow and encourage adlib performance based on the script, but you should give a remark for it later and point out any language mistake if there is.

Debate requires fluent English speaking and considerable preparations. Many other abilities are also necessary for a qualified debater. And even a native speaker might not do well in it. That is to say, however, it can effectively improve English skills.

\section{B. Reading \& Writing}

Reading and writing are the other fundamental language skills apart from speaking and listening. The number of words you know determines the difficulty and complexity of the material you can read and understand. Words are the basis of any human language and all cultural features can be reflected though them. Failure to develop an extensive reading vocabulary will definitely hold you back in your efforts to improve your reading speed and your comprehension. Vocabulary teaching shall involve those words which may have special meanings in specific situations or imply some intent. Learners usually get confused and make mistakes as they come to these sorts of words. So, knowing the literal meanings of a large quantity of words is still far from mastering a foreign language and this requires the teacher to give each word an accurate and comprehensive explanation during vocabulary teaching. Another kind of words which refer to some items in one culture but are vacant in another should raise the students' attention. When expressing these items or translating such words, translate them by pronunciation first and then give a general explanation. In sum, whatever the word is, the teacher needs to help students understand it thoroughly, which means they know the exact literal meaning, in which situation they can use it and whether the word is used to praise or abuse.

During the reading and writing course, what the students should be informed first is that English articles are constructed strictly in logic while Chinese ones are managed through a general idea. So when reading an English passage, trace the logic clue. To help the students understand it better, teachers could provide a tree of the inner logic structure, a relationship chart of characters involved in the story or a picture of some traditional item in another country. Similarly, when forming an article, the student is expected to show a clear logical structure. This means a number of related words, which are usually left out in Chinese articles, are necessary to a well-organized English one. However, foreign language learners sometimes misuse his native language logic to organize an article unconsciously. Specifically, an English article written by a Chinese student can still totally confuse a native English speaker, even there might be no spelling or grammar mistake in it. To make progress in this aspect, more reading, more writing and, of course, more correcting after writing are definitely effective. Meanwhile, reciting some typical paragraph or the whole article is also necessary for the learners, for the materials they have memorized will serve as models and make thing easier when writing their own ones.

\section{Self-study Guiding}

Self-study compensates for the limits of class. The foreign scholars have found the importance of self-study in language learning since 1970s. They found that studying on one's own initiative is much more effective than being taught passively. The active learners have a clearer aim, which leads more efficiency and better result. On the other hand, two or three English lessons per week is the maximum a college can afford, which is far from enough for language learning. So, guiding the students make out proper and regular self-study plans is of great significance. Meanwhile, there are many forms of self-study that are not considered as study traditionally, but they really help to improve English skills and some of them could be extremely fun.

American TV dramas are intended for native English speakers. The lines in them are exactly the hottest phrases and sentences that are used nowadays, and the customs and culture could not be more traditional. Meanwhile, most of the dramas are comedies and are really fun. They are worth watching more than once to learn the useful lines and 
traditional customs. Compared to those in TV drama, lines in the movies could be more standard and sometimes literary. There are many classic lines and memorizing some of them will make your English more attractive.

At any time or anyplace, when a new English word come to you, look it up in the dictionary. This is a long term work. Although there is no direct link with culture, words are the basis anyway. So keep it on, things will be great different.

\section{CONCLUSION}

Cross-cultural communication skills are full of significance for an English learner and nowadays, many scholars have recognized that a good cross-cultural communication skill is the key to a successful talk. However, the survey we have conducted shows that is what our Chinese college students are weak in. The reasons of the conditions mainly lie in four aspects: expressions influenced by Chinese culture, poor knowledge of English customs, lack of real communications with foreigners and improper guidance from the examination-oriented education system. So, finding some new teaching methods is high on the agenda to change the status quo. Culture teaching is what we recommend. Specifically, it can be divided into two parts, speaking \& listening and reading \& writing. Different from tradition courses, these courses ought to contain more practical exercise. We suggest five forms of exercise, in details, conversation, storytelling, oral report, role play and informal debate, for speaking \& listening courses. All these practices are meant to give the student a chance to experience real communications in English and real English culture, which is the best way to improve a foreign language. Similarly, the reading and writing course is composed with the same concept. Additionally, self-study, as we mentioned in the last part, could improve students' English abilities throughout a long process with constant efforts. Incorporating cross- cultural communicative approach to English teaching will help to foster better understanding and using of the target culture.

The present study is mainly concerned with cross-cultural communication competence among undergraduates of science and engineering in China. However, its findings and conclusions may have implications for students at other levels and in other parts of the world.

\section{APPENDIX. TeST ON INTERCULTURAl COMMUNICATION COMPETENCE}

Part I There are 15 statements in this part. Each item has an underlined part. Read each item and decide whether the underlined part is appropriate or inappropriate.

1. Dr. Smith, over 60, invited Li Ming to his birthday party. Li Ming brought him a China god of longevity as a present.

2. When you have a conversation with your English teacher who is a native speaker of English, you mustn't have a prolonged eye contact with him.

3. When you are eating with an English friend, you wish him, "Good appetite!"

4. In the English speaking countries you usually first introduce a man to a woman, not the other way round.

5. If it is very cold and Mary, an American student, wears thin clothes, you should suggest that she wear more clothes.

6. Mary is a foreign student in China. She met Li Mei and said to her: "I was told that you won the 100-meter race in the track meet this morning. Congratulations." Li replied, "Just lucky."

7. Dr. Smith, your supervisor, telephoned to invite you to have dinner with his family. You replied, "Thank you. All right. I'll try to come."

8. Mrs. Smith was about the same age as Li Mei's grandmother, so immediately Li called her "Grandma."

9. An American mother and her lovely four-year-old daughter are playing on the square. You go up and touch the girl's hair and face.

10. Bob wins the speech contest. Wang Lei says to him: "You are a lucky dog."

11. Zhao Ming visited his foreign friend, and about 10 o' clock, he said suddenly: "I've got to go now. Good-bye."

12. Professor Smith was going to return to America. One of his students sent him china engraved with many dragons.

13. If you are a male and introduced to an English speaking lady, you do not take the initiative in shaking hands unless she holds out her hand first.

14. Miss Li teaches some American students Chinese. One day, John didn't come to the class. She asked his roommate, Peter, how John was.

15. When you walk with a close friend with the same gender as yours in the street, you intimately put your arm around your friend's shoulders or hand while walking.

Part II There are 10 statements in this part. Read each item and decide whether they are true or false.

16. If you smile at or greeted a stranger in the street or in the park, you would probably be ignored as the stranger might take you as a hooligan.

17. If one is going to invite his fellow students to a party, he must invite them one or two days in advance.

18. American people often propose meals together without intending to pay for the other person.

19. In the United States it is not uncommon for parents to put a newborn baby in a separate room.

20. "Thank you" is used frequently as a polite response to different favors and compliments and is often used automatically. 
21. In times of financial difficulty, nuclear family members (father, mother and children) often borrow money from a bank rather than from relatives.

22. Most English swear words have to do with Christian religious terms or names.

23. As black is often associated with negative qualities, in business English, in the black means running a business at a loss, not making profit.

24. When you want to compliment your young English friend's new coat, you can say, "I like your new coat!" 25.25. When someone else shows you a thumps-up gesture, he means "You're so great."

Part III. From the four given choices, choose the most suitable one.

26. In the West, bats are considered to be
A. a sign of fortune
B. a sign of misfortune
C. a sign of happiness
D. a sign of high social status

27. There is a proverb saying that "An Englishman's house is his castle." It means
A. his house is strongly built
B. his house is his privacy
C. he is ready to fight
D. nobody is permitted to enter his house

28. In the western countries, 13 and Friday is thought to be unlucky, and this is because

A. Jesus had the last dinner with his disciples on Friday

B. Friday is the last day of the weekdays

C.13 is the biggest indivisible number

D.13 is the last day before pay day

29. Halloween Day in the West is similar to a festival in China, and this might be
A .Lantern Festival
B. Dragon Boat Festival
C. Zhongyuan Festival
D. the Double Ninth Festival

30. An English friend invites you to have dinner at 6:00 p.m. with his family. You would arrive at
A. 5:50
B. $6: 30$
C. $6: 15$
D. $5: 10$

31. Xiao Ma is an interpreter. One day a foreign visitor, Mr. Brown, talks to him. Brown: Your English is quite fluent. Ma:
A. Thank you, it's kind of you to say so
B. No, no, my English is poor
C. No, not at all
D. Oh, no, far from that. I still have a long way to go

32. Li Ming met his English teacher, Dr. Jones, outside the classroom. Li:
A. Hi, teacher Jones
B. Hello, teacher
C. Morning, Dr Jones
D. Good morning, teacher Jones

33. When you are invited for the first time to the Brown's house and offered a cup of coffee, you
A. should rise and accept it
B. should rise and say, "Thank you"
C. should make a slight rising movement
D. can remain seated and accept it with a smile and say, "Thank you"

34. Generally hosts do not offer food more than once or twice because they
A. do not expect you to be hungry
B. expect you to refuse politely
C. expect you to dislike the food
D. expect you to say immediately what you really want

35. Which topic is more appropriate to discuss immediately after an introduction?
A. Marital status
B. Religion
C. Occupation
D. Age

36. In the USA, a speaker finishes giving a speech and nobody asks questions about his topic. It shows that his speech is
A. very successful
B. a complete failure
C. very difficult to understand
D. very convincing

37. You're in part of town where your old English friend lives. Do you
A. go to her house and give her a surprise
B. phone and find out if it's convenient for her first
C. phone and fix a meeting for another day
D. None of the above

38. What will your English friend do when he accepts your gift for his birthday? He will
A. accept it without any words
B. open it and watch it by himself
C. open it and watch it before you and say "Thank you"
D. express thanks to you without opening it

39. Li: "What do you think of the film?" Smith: "I can't praise this film too highly." By this, Mr. Smith means

$\begin{array}{ll}\text { A. this film is just so-so } & \text { B. this film is good that it deserves praise }\end{array}$

C. this film is not good

D. this film is OK, but doesn't deserve praise

40. Xiao Li works as a secretary in American company. One day she worked very late. Her boss said to her, "Thanks a lot. You were a big help." Xiao Li replies:
A. It's my pleasure
B. Never mind
C. You're welcome
D. Oh, it's nothing

\section{REFERENCES}

[1] Hu Wenzhong. (2005). On empirical research in intercultural communication. Foreign Language Teaching and Research 5, 323-328. 
[2] Samovar, Larry A. \& Richard E. Porter. (1994). Intercultural communication. California: Wadsworth Publishing Company.

[3] Savignon, S. J. (2007). Beyond communicative language teaching: What's ahead? Journal of Pragmatics, 39, $207-220$.

[4] Song, L. (2008). Exploration of a conceptual framework for intercultural communicative English language teaching in China. Ph.D. dissertation, 4-5.

[5] Xu, L.S. (2006). Studying language and its use: An intercultural approach. Shanghai: Shanghai Foreign Language Education Press.

Mei Guo was born in Wuhan, China in 1973. She received her master's degree in English Languages and Literature from Wuhan University, China in 1998.

She is currently a lecturer in the School of Foreign Languages, Dalian University of Technology, Dalian, China. Her research interests include cross-cultural communication and western culture.

Yuan Sun born in Nanjing, China in 1994 is a college student in Dalian University of Technology. He began to learn English from a very young age and his excellent English abilities helped him become an assistant of Mrs. Guo. 